\title{
Sustaining The Progress To Improve Physics Education
}

Wathiq Abdul-Razzaq, West Virginia University, USA

\begin{abstract}
One of the problems we face in teaching introductory physics courses at the college level is that about 2/3 of students never had physics prior coming to college. Thus, many students find it very difficult to learn physics for the first time at the relatively fast-paced teaching of college physics courses. Sometimes the drop/failure/withdrawal rate at West Virginia University is as high as $65 \%$ ( 2/3) for the introductory physics courses taken mostly by pre-engineering students. Obviously, there is a strong connection between the students' physics backgrounds and the success rate of passing physics. With the support of the National Science Foundation (NSF) funding, we created an intervention course for a small group of students who did poorly in the first test in one of the physics courses. This intervention course ran concurrently with the regular physics course, but started at the fourth week of class after the first test. Students who received our intervention showed significant improvement in the subsequent physics tests. ${ }^{1}$ The recruitment of the students and the supervision of the course were the result of a unique collaboration between the College of Engineering and the Physics Department. After the expiration of the NSF grant, the intervention course was cancelled due to the lack of funds. The labs associated with physics classes, however, give us the opportunity to continue the advancement of physics learning after the ending of the NSF grant.
\end{abstract}

Keywords: Funding, Physics Education, Introductory Labs

\section{INTRODUCTION}<smiles>[AlH2]</smiles>

tudents are required to take physics courses in college whether they desire to be engineers, medical doctors, pharmacists, chemists, geologists, forensic program experts, dentists, teachers or, of course, physicists. Even though physics is an essential course in college, many students enter college without a physics background. These students face many difficulties trying to learn physics in college at a pace which is not designed for beginners. To improve physics learning in colleges, many instructors/researchers began speaking about the failure of traditional physics courses and started testing alternative teaching methods. Measures such as varying class size, introducing new types of group work, adding interactive computer simulations, etc., have been tried. ${ }^{2}$ In testimony before Congress on national competitiveness, Nobel Laureate in physics C. Wieman stated that undergraduate science education can be dramatically improved for all students. His challenge is for colleges and universities - especially large research universities - to invest in changing how science is taught. ${ }^{3}$ One large university took the measure of eliminating some important topics in their algebra-based physics course after being convinced that students could not master all the required material in the limited time allotted. ${ }^{4}$

\section{THE MAJOR PROBLEM}

The fact remains that in most research universities, there are over 100 students (sometimes 300 students) in a physics class. These students are with vast differences in math and physics backgrounds -- this could be the main problem we face in physics education in college. It is impossible for the instructor to tail her/his lecture to the level that is optimally useful to students. You need external funding to hire additional teachers if you want to divide students into small groups according to their math and physics backgrounds. Kadanoff ${ }^{5}$ writes "US students, who match up to the best in the world in early grades, fall behind in middle school and find themselves rather poorly trained in science and mathematics in their high-school years. At the high-school level, the US has a substantial shortage of qualified physics teachers". 
The NSF funding allowed us at West Virginia University (WVU) to help some weak students via an intervention course taught by a carefully selected instructor. Face-to-face discussion in physics as well as guidance on organization, time management and personal development was the way that our intervention course was handled. Our data ${ }^{1}$ showed that students who received our intervention showed significantly greater improvement in their understanding of physics concepts and thus was related to higher grades at the end of semester. See figure 1.

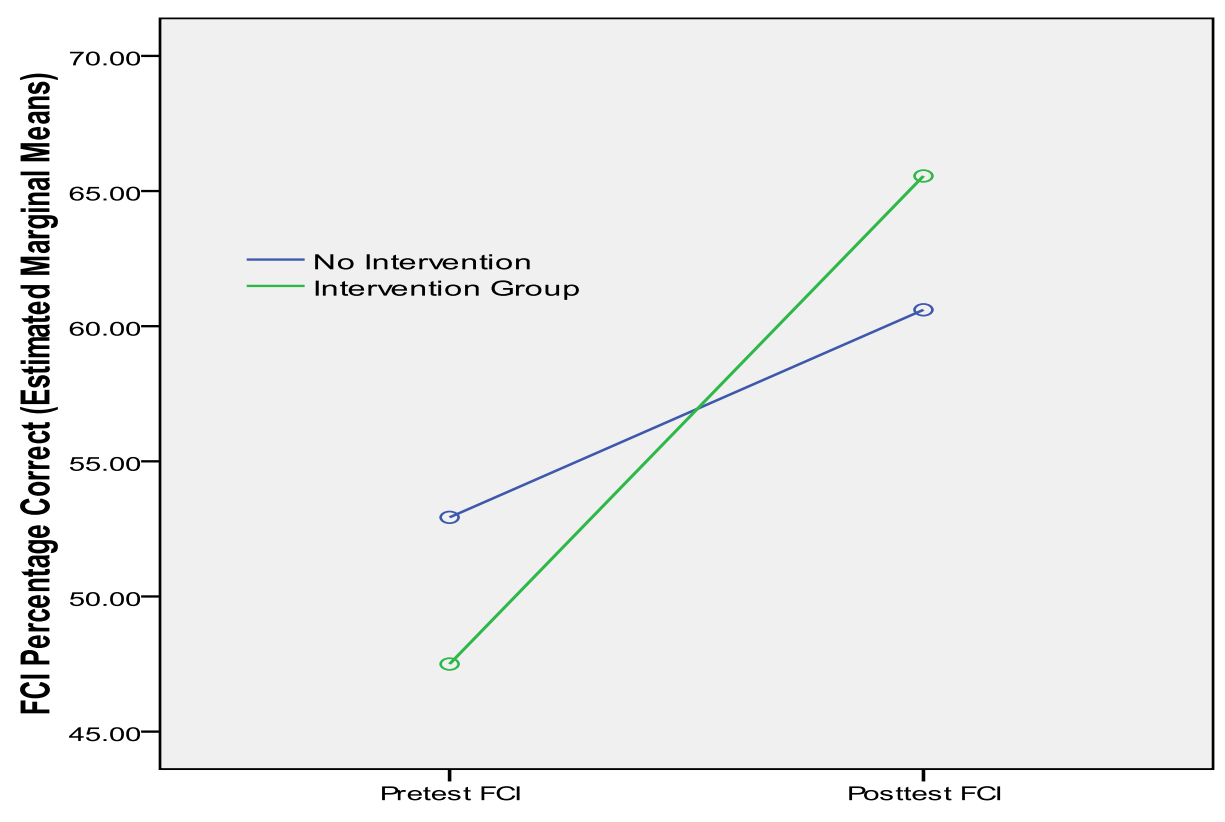

Figure 1: Students in the Intervention Group Showed Significantly Greater FCI (The Force Concept Inventory) Gains ${ }^{1}$

\section{THE FUND ENDED}

Our success in helping weak students understand physics principles, as well dealing with their attitude and study habits, has ended with the expiration of the NSF grant. There was no way to continue to offer this intervention course without seeking external funding. The problem was that this course was considered "research activities" as it was supported by a NSF grant. However, this course falls under the teaching mission if the university continues to offers it after expiration of the grant. With budget cuts, there is a thrust to reduce the number of courses offered at WVU, let alone supporting intervention courses.

\section{SUSTAINING THE PROGRESS}

The only option left for us to sustain the progress we made to physics education at WVU after the expiration of NSF grant was through the lab associated with the physics courses. Even though we placed about 100 students in the physics lecture room, we placed only about 20 students in the lab with one instructor. Our intervention course had a similar small number of students. Thus, lab teaching (like in the intervention course) can center on participatory behavior, something we cannot do in the large lecture hall. With no exams in the labs, the instructor can develop an atmosphere that allows students to overcome their anxieties. Students can enjoy the process of logically realizing the principles of physics through lab experiments. With such a small group of 20 students, the instructor can make interactivity of the students central to encouraging the development of more appropriate and enjoyable work and thinking habits. 
Moreover, and unlike in lectures, all students tend to attend the labs including the lazy students who normally miss many lectures. That is because lab grade constitutes about $15 \%$ of the course grade and no exams are given in the lab. Almost every student gets a high grade in the lab by simply presenting a straightforward lab report about the work performed in the lab.

We are currently exchanging our lab experiments with home-developed experiments. Well designed experiments lead to the development of curiosity within the students. A curious nature is extremely valuable toward engineering studies, medical studies, science studies or any other study. We plan to use proper films in the labs to show the relation between physics and other fields of study, such as real-life applications in engineering, health, biology etc. In large lecture rooms, most professors are too busy trying to cover the curriculum that only few of them show demos or films in class to demonstrate the concepts. We also plan to use whatever worked in our NSF supported intervention class in our labs to get the benefits the students got through the intervention course.

\section{SUMMARY AND CONCLUSION}

Physics is an essential course in college. However, physics is found difficult by many students largely because we go too fast in teaching it in the lecture rooms. And there is another cause that makes physics hard; that is the demand to make our students solve problems that are not simple and not similar to homework problems. ${ }^{6}$ These factors are devastating to students who never had physics in high school and never acquired a decent math background. Moreover, it has been learned that a mastery of problem-solving, of the kind traditionally central to physics courses, does not necessarily lead to an understanding of physics concepts. ${ }^{6}$ Without external funding, we have only one option to improve physics education at West Virginia University, and that is through the already existing labs associated with physics classes. Unlike the lecture halls, the labs are designed for small group of students. The instructor could easily identify and work with weak students and enhance the knowledge of the better students. At West Virginia University, we have been revising lab experiments to specifically promote student learning, critical thinking, increase student interest and engagement, and model the process of experimental science. The vision is to simultaneously focus on students' conceptual development, their laboratory skills, their views about physics and attempt to reference real-world situations that are engaging. Improving physics education through the labs has even two advantages over intervention courses: (1) intervention courses require students to enroll in an extra course that many students do not want to do, while we get nearly all the students in the labs. (2) external funding is not required to improve physics learning through the labs; the university already has in place the mechanism for supporting the labs from paying lab instructors to purchasing equipment.

\section{AUTHOR INFORMATION}

Dr. Wathiq Abdul-Razzaq received his PhD in 1986 from the University of Illinois at Chicago. He completed his post-doctorate work at Michigan State University. Currently he is Professor of Physics and Director of Introductory Physics Curriculum at West Virginia University. He has had research activities in diverse areas including studies of magnetic and transport properties of thin films, studies of magnetic nanoparticles, and applied studies related to health and environment. Recently he does research in education.

\section{REFERENCES}

1. R. Curtis, B. Lewis, W. Abdul-Razzaq, and G. Winn, American Society for Engineering Education Annual Conference \& Exposition, Article AC 2009-455 (2009).

2. Chronicle of Higher Education, Feb. 9 (2007).

3. Carnegie Foundation for the Advancement of Teaching: www.carnegiefoundation.org

4. E.F. Radish and D. Hammer, American journal of Physics, Page 629, 7, 77 (2009).

5. L. Kadanoff, Page 8, September, Physics Today (2006).

6. M. Sobel, The Physics Teacher, Page 346, Vol. 47, September (2009). 
NOTES 